\title{
Stress-Induced Alterations in Estradiol Sensitivity Increase Risk for Obesity in Women
}

\author{
Vasiliki Michopoulos, $\mathrm{PhD}^{1,2}$ \\ ${ }^{1}$ Department of Psychiatry and Behavioral Sciences, Emory University School of Medicine, Atlanta, \\ GA; ${ }^{2}$ Yerkes National Primate Research Center, Atlanta
}

Corresponding Author:

Vasiliki Michopoulos, PhD

Department of Psychiatry and Behavioral Sciences

Emory University School of Medicine

49 Jesse Hill Jr. NE, Atlanta, GA 30303

E-mail: vmichop@emory.edu

Keywords: stress axis, obesity, glucocorticoids, estradiol, sex differences, animal models 


\section{Abstract}

The prevalence of obesity in the United States continues to rise, increasing individual vulnerability to an array of adverse health outcomes. One factor that has been implicated causally in the increased accumulation of fat and excess food intake is the activity of the limbic-hypothalamic-pituitary-adrenal (LHPA) axis in the face of relentless stressor exposure. However, translational and clinical research continues to understudy the effects sex and gonadal hormones and LHPA axis dysfunction in the etiology of obesity even though women continue to be at greater risk than men for stress-induced disorders, including depression, emotional feeding and obesity. The current review will emphasize the need for sexspecific evaluation of the relationship between stress exposure and LHPA axis activity on individual risk for obesity by summarizing data generated by animal models currently being leveraged to determine the etiology of stress-induced alterations in feeding behavior and metabolism. There exists a clear lack of translational models that have been used to study female-specific risk. One translational model of psychosocial stress exposure that has proven fruitful in elucidating potential mechanisms by which females are at increased risk for stress-induced adverse health outcomes is that of social subordination in socially housed female macaque monkeys. Data from subordinate female monkeys suggest that increased risk for emotional eating and the development of obesity in females may be due to LHPA axis-induced changes in the behavioral and physiological sensitivity of estradiol. The lack in understanding of the mechanisms underlying these alterations necessitate the need to account for the effects of sex and gonadal hormones in the rationale, design, implementation, analysis and interpretation of results in our studies of stress axis function in obesity. Doing so may lead to the identification of novel therapeutic targets with which to combat stress-induced obesity exclusively in females. 


\section{Introduction}

Rates of obesity in the United States (US) continue to rise, with recent 2014 estimates placing the prevalence at $38 \%$ of the population [1], which is expected to increase to $50 \%$ by 2030 [2]. Importantly, obesity is a significant risk factor for a number of adverse health outcomes including type II diabetes, cardiovascular disease, stroke, some types of cancers, reproductive compromise, and musculoskeletal

problems [3, 4]. Despite significant medical advances for managing these somatic illnesses, obesity-related disorders account for nearly 112,000 excess deaths in the US [5]. For these reasons, understanding the factors that produce an obese phenotype is critical for identifying interventional strategies that reduce the health burden imposed by obesity and obesity-related adverse health outcomes.

Obesity is primarily attributed to excess caloric intake beyond the energetic needs of an organism. Factors that promote eating while an individual is satiated have recently gained attention as potential interventional targets. For instance, exposure to chronic psychosocial stressors in a dietary environment wherein calorically dense diets (i.e. high in fats and sugars; CDD) are available results in stress-induced emotional eating and increased body weight [6]. The physiological response of the limbic-hypothalamicpituitary-adrenal (LHPA) axis in response to chronic stressor exposure results in glucocorticoid secretion from the adrenals, and release of cortisol promotes the consumption of extra calories and, over a long enough period of time, weight gain [7]. In humans, increased waist-to-hip ratios (WHR) and sagital diameter are associated with diminished glucocorticoid negative feedback inhibition of the LHPA axis as assessed by a dexamethasone suppression test [8], increased cortisol reactivity to a stressor [9], and blunted morning cortisol levels [10, 11].

The earliest indication that increased activity of the LHPA axis results in an obese phenotype comes from our characterization of excess glucocorticoids and increased visceral fat in Cushing's Disease $[4,12]$. The causal role for glucocorticoids in promoting food intake and weight gain was cemented by studies in rodents [13-15] and humans wherein administration of exogenous glucocorticoids resulted in augmented abdominal obesity $[16,17]$. While exogenous glucocorticoid administration clearly results in weight gain, the effects of stress-induced LHPA dysregulation on "comfort food" intake and energy balance 
are not consistent across animal models [18] and humans [19]. Factors including type and duration of stressor, methods of LHPA assessment, and dietary environment all influence the effects of stress exposure and LHPA axis activity on food intake and metabolism [18, 19].

One important factor that continues to be understudied in the realm of obesity and LHPA axis dysfunction is sex. Some studies in rodents and in women indicate that females are protected from dietinduced obesity, insulin resistance, and inflammation in response to a CDD [20], suggesting that ovarian hormones such as estradiol may be an important protective factor against obesity in women. However, other reports indicate that women are twice as likely as men to suffer from stress-induced disorders, including depression, anxiety, emotional feeding and obesity [21-27]. This discrepancy in the risk for obesity in females may be due to the disregard of addressing how exposure to stressors and dysregulation of the LHPA axis may alter the behavioral and physiological sensitivity of gonadal hormones in females, thus increasing risk for adverse health outcomes such as emotional eating and obesity.

The current review will summarize the literature from translational animal research describing the effects of stressor exposure and LHPA axis activity on appetite regulation and the development of obesity, while concurrently emphasizing the overall lack of animal models and studies addressing the etiology of stress-induced obesity specifically in females. A non-human primate model of chronic psychosocial stress exposure will be discussed to emphasize how stressor exposure may alter sensitivity to estradiol (E2), the primary ovarian hormone, thereby increasing risk for adverse health outcomes, including emotional eating and fat accumulation. Lastly, potential mechanisms by which stressor exposure and LHPA axis function lead to such phenotypes in females will be considered.

\section{Translational Rodent Models Used to Study Stress-induced Obesity Have studied Males Almost}

\section{Exclusively.}

A stressor is any perceived threat that jeopardizes the well being of an organism and induces physiological changes that activate systems crucial for surviving the perceived stressor and returning back to baseline homeostasis $[28,29]$. Stressors can be physical or psychological in nature, can be discrete 
events or continuous assaults on homeostasis, and can have both physiological and behavioral consequences for an individual organism [30]. The rapid activation of the sympathetic nervous system and the LHPA axis in response to a threat likely evolved to promote survival from acute physical stressors [28, 30]. However, stress exposure in modern day human societies increasingly takes the form of psychological stressors that are experienced on a daily basis [30]. Continuous activation of the LHPA axis under such conditions is deleterious to individual health as evidenced by the increase of disorders whose etiology stems from a dysregulation of LHPA neuroendocrine circuits, including obesity [29, 30].

One approach undertaken to emulate the downstream effects of chronic stress has been exogenous administration of high levels of glucocorticoids. While these studies do not subject animals to actual physical or emotional stressors, they mimic elevated levels of corticosterone that are associated with chronic exposure to stressors in rodents [31-33]. Chronic corticosterone administration via drinking water in male rats over three weeks disrupts endogenous adrenocorticotropic hormone (ACTH), corticosterone and glucose levels [34]. Administration of exogenous glucocorticoids in male rodents also results in augmented abdominal obesity under dietary conditions wherein only a prudent, low calorie chow diet (LCD) is available $[13,15]$, as well as when a CDD is offered exclusively [14]. These data from male rodents recapitulate increases in weight and adiposity due to exogenous glucocorticoid treatment in humans [16, 17]. However, data generated from these glucocorticoid manipulations should be interpreted with caution as the manipulation results in the loss of the normal diurnal glucocorticoid rhythm that has been shown to be dysregulated in other stress models as well as in human psychopathology [35-37]. Furthermore, chronic exogenous corticosterone administration leads to adrenal atrophy [34], which is contrary to the adrenal hypertrophy that has been reported in other animal models wherein subjects are exposed to chronic stress [38].

Repeated immobilization or restraint stress is another common model for chronic stress exposure in rodents. Animals are placed in plastic tubes that immobilize their lateral and forward movement, typically for 30 minutes a day, for seven consecutive days $[39,40]$. Daily restraint increases coticosterone levels after subsequent bouts of restraint as well as ACTH levels in male rodents [41]. Male rats that undergo 
chronic restraint under conditions wherein LCD is available show alterations in metabolic phenotype, including an attenuation of body weight [40]. More recently however, the chronic restraint model in male rats has been critical for studying how dietary environment and access to CDD interacts with stress exposure to alter feeding behavior and metabolism $[42,43]$. These studies indicate that elevation of glucocorticoids in the presence of CDD shifts the dietary preference towards intake of these comfort foods in the face of stressor exposure [42, 43], similar to what is described in humans [44].

A different model of physical chronic stress exposure in rodents is chronic intermittent cold stress exposure wherein animals are subjected to a few hours a day of low temperatures ranging from $4-6^{\circ} \mathrm{C}$, for a week. This chronic intermittent cold stress model has been critical in elucidating, via neurochemical, neuroanatomical, and lesion studies, the underlying circuits that are activated by acute stress superimposed on a background of chronic cold stress in male rats $[45,46]$. Additionally, this cold chronic stressor has been used to determine how adrenalecotomy, and thus glucocorticoids, interact with a chronic stress background to modulate the activity of the LHPA axis in response to subsequent stressors in male rats [47]. Importantly, chronic intermittent cold stress exposure in parallel with access to only a LCD increases food intake and fat deposits in male rodents [31].

While the above mentioned physiological and physical stress paradigms have been leveraged to understand the effects of chronic stress on the emergence of an obese phenotype, these models in male rodents induce physiological and behavioral responses that are exclusive to the stressor employed in the model. Animals subjected to these physiological and physical procedures adapt to stressor exposure, such that they habituate and show attenuated HPA responses to stressor exposure or a faster return to baseline conditions, or they stop eliciting hormonal and behavioral responses to the stressor [45, 48-52]. Paradigms and models wherein the chronic stressor exposure is both unpredictable and uncontrollable results in continued activation of behavioral and physiological responses to stress, similar to what has been described in humans. Such translational animal models have been studied to assess the effects of chronic psychosocial stress exposure on appetite regulation and the emergence of obesity. 
Several rodent models of chronic stress have been employed to assess the effects of LHPA axis dysregulation on the emergence of an obese phenotype by using psychosocial stressors that mimic human experiences. For instance, the chronic variable stress (CVS) paradigm exposes rats to six weeks of repeated mild physical (restraint, home cage tilt, cold stress) and psychosocial stressors (social isolation) [53]. CVS results in increased basal corticosterone and ACTH, as well as increased adrenal size and alterations in neurobiological markers of LHPA axis function [53]. Overall, the dysfunction within the LHPA axis due to CVS exposure is associated with altered behavioral phenotypes, including deficits in fear learning, emotional arousal in male rats [54] and anhedonia in both female and male rats [55, 56]. Furthermore, female rats subjected to CVS show altered appetite regulation and metabolism in a dietary condition wherein only a CDD was available [57]. CVS-subjected females on a CDD eat significantly less calories that control females in the same CDD diet condition, and do not show an increase in weight that was seen in control animals [57]. While these data suggest that CVS in females attenuates caloric intake and body weight and adiposity increases compared to control animals in a CDD environment, the lack of a stress-effect seen in other studies may be due to the fact that females in this study were not given a dietary choice [57]. Indeed, previous rodent data has shown that the presence of a dietary choice condition, wherein both a LCD and CDD are available, sustains intake of high caloric diets [58].

An ethological social stressor is also employed in two other rodent models of psychosocial stress exposure used to assess the effects of LHPA axis activity on food intake and the emergence of obesity. The social defeat model in male rodents (rats and hamsters) repeatedly exposes an animal to a more aggressive intruder on a single day. This social defeat results in the subordination of the socially defeated male rats and hamsters, and produces sustained activation of the LHPA axis $[59,60]$, immune dysfunction [61] and specific changes in neurochemical circuits within mesolimbic regions [60,62]. Behaviorally, social defeat in male rodents is associated with anhedonia, decreased activity, and increased depressive-like behaviors [60]. Additionally, socially defeated male hamsters that only have access to a LCD increase food intake, body mass, and white adipose tissue $[62,63]$. 
The visible burrow system (VBS) is another rodent model of psychosocial stressor exposure used to study the effects of stress exposure on food intake wherein groups of male rats are housed socially with several females for two weeks [64]. A dominance hierarchy is formed immediately between males within the VBS, and the subordinate males behavioral and physiological phenotypes characteristic of chronic stress exposure. For example, subordinate males have increased basal corticosterone levels and enlarged adrenal glands [65]. In dietary conditions wherein only a LCD is available, subordinate males have attenuated body weight that is attributable to decrease adipose tissue that results in hypoleptinemia [6568]. However, when animals are given intermittent recovery periods from social housing during which previously subordinate males respond differently than dominant males, most typically with excess food intake and weight gain when maintained on a LCD only $[67,69]$.

Together, the CVS, social defeat, and VBS models of chronic stress exposure employ psychosocial adversity similar to those experienced by humans that results in physiological and behavioral phenotypes characteristic of adverse chronic-stress states in people. The data generated from these rodent models have significantly advanced our understanding of how chronic exposure to social stressors and LHPA dysregulation produce changes in appetite and metabolism that contribute to obesity. However, while these models employ a repeated uncontrollable or unpredictable type of stressor, face and construct validity is diminished because the stressor is discontinued. Furthermore, only one of the rodent models described above has been used to exclusively assess the effects of stress and LHPA axis activity on feeding behavior in females. While some models are limited due to the ethological nature of the stressors, such as the VBS that only produces male dominant and subordinate rats [65-68], the other rodent models discussed have studied male rodents $[42,45]$. The CVS rodent model of unpredictable chronic stress exposure is one of the few rodent models that have been used to study sex differences in the development of the responses to CVS and the underlying mechanisms that might be responsible for these differences $[57,70]$.

The consideration of sex is critical in our studies of the stress axis and obesity, as women exposed to stress are more likely to increase food intake compared to men [21, 71]. Studies in women have shown 
that females who show a greater cortisol response to an acute stressor also exhibit increased caloric intake after stressor exposure [72]; a similar result has been reported in female rhesus monkeys [73].

Furthermore, this increased cortisol response to a stressor in women has been linked to greater amount of central fat mass [9] that is also associated with increased urinary free cortisol levels [74]. Obese women who gain weight following a stressful event show significantly higher levels of urinary free cortisol than women who have nonstress-related obesity [75]. Augmented urinary free cortisol levels in obese women are also associated with increased intake of CDD [76], supporting the notion that increased LHPA axis activity following exposure to acute psychosocial stressors in women shifts dietary preferences such that CDD are preferred $[71,72]$. These clinical data highlight the need to study the interaction of obesity and LHPA axis activity in a sex-dependent manner, and as such, more robust, translational animal models in females are necessary.

\section{Social Subordination in Female Macaques is an ethologically relevant translational model with which to study Stress-induced Obesity in Females.}

One translational model of psychosocial stress exposure in females that is characterized by constitutive exposure to adverse social environment, similar to that experienced by people and implicated in the development of stress-induced disorders, is that of social subordination in socially housed female macaque monkeys [77]. Macaque social groups are organized by a linear dominance hierarchy that is imposed by the threat of aggression or harassment from higher-ranking individuals towards lower-ranking individuals within the hierarchy $[78,79]$. Subordinate social status in female macaques results in an array of adverse health outcomes that mimic those seen in humans [80] (summarized in Table 1), such as a proinflammatory state [81]. Importantly, subordination in female macaques is associated with alteration in LHPA axis activity $[82,83]$, including hypercortisolemia due to diminished glucocorticoid negative feedback of the LHPA axis [84, 85], altered sensitivity to ACTH [82, 86], and increased adrenal size [87].

The dysregulation of the LHPA axis in subordinate females is coincident with augmented caloric intake when a CDD is made available in a choice diet condition wherein a LCD is also available [73]. This 
hyperphagia in the presence of a CDD is associated with increased meal and snack size [88], an increase in body weight after three weeks of CDD availability, and a decrease in anxiety-like behavior in subordinate females [35]. CDD availability in female rhesus monkeys results in increased basal cortisol levels, regardless of social status $[35,73]$. Similarly, intake of CDD increases LHPA axis activity in rodents [8991] and in humans [8]. In a more recent study, administration of a $\mathrm{CRH}$ receptor antagonist attenuated overall caloric intake in subordinates [92], indicating that stress-induced emotional eating in subordinate females with access to both a low calorie diet and CDD is sustained by LHPA axis activity.

Importantly, the social subordination model in female macaques has also been leveraged to assess how exposure to chronic stress alters behavioral and physiological sensitivity to E2. E2 replacement in ovariectomized monkeys increases basal levels of glucocorticoids as well as diminishes negative feedback inhibition of the LHPA axis [84]. Exposure to social subordination in female monkeys further enhances the escape from glucocorticoid negative feedback [84], indicating that E2 and stress exposure can synergize to influence activity of the LHPA axis. This altered sensitivity to E2 on LHPA axis function in subordinate females is coincident with a decreased behavioral sensitivity to the anxiolytic actions of E2, as replacement of E2 to ovariectomized subordinate monkeys does not reduce levels of anxiety-like behaviors as effectively as E2 does in dominant females [93].

Another documented alteration in physiological sensitivity to E2 that has been observed in subordinate monkeys relates to E2 modulation of the hypothalamic-pituitary-gonadal (HPG) axis. Subordinate females show enhanced E2 inhibition of the HPG axis that results in attenuated luteinizing hormone (LH) levels [94]. This altered HPG sensitivity in subordinate females is exacerbated by pharmacological increases in cortisol levels [94], suggesting that the increased incidence of anovulation and luteal phase deficiency seen in subordinate versus dominant females is due to sustained LHPA axis activity in subordinate females [95, 96]. Together, these data indicate that exposure to chronic stressors alters physiological sensitivity to E2 in subordinate females, suggesting that a similar alteration in sensitivity to E2 may influence the regulation of feeding behavior and increase risk for obesity under complex dietary conditions. 
E2 is typically considered an anorexic hormone [97, 98], as food intake during the follicular phase of the menstrual cycle, wherein E2 levels are high in women, is attenuated in comparison to the luteal phase of the cycle [99-102]. Similarly, E2 replacement in ovariectomized adult rhesus monkeys to serum levels characteristic of the follicular phase significantly reduces meal size and number [98]. However, this anorectic effect of E2 is diet dependent, as it is only seen when animals are fed a LCD [98]. When female monkeys are maintained in a dietary environment where both a LCD and CDD are available, E2 does not attenuate total caloric intake [98] and increases preference for the CDD [98]. Additionally, this effect of diet on E2's modulation of food intake and preference seems to be dependent on social status, as E2 in dominant females attenuates food intake whereas it increases overall caloric intake in subordinate females [98]. While these data from adult female monkeys support the notion that chronic stress alters the ability of E2 to regulate food intake, thus increasing the risk for obesity in females, the mechanisms by which this occurs remain unclear.

\section{Possible mechanisms by which stress exposure alters E2's actions of food intake and metabolism.} Opposing Actions of Glucocorticoids and Estradiol on Regulators of Metabolism and Food Intake.

Glucocorticoids, including cortisol and corticosterone, drive downstream alterations in metabolic signaling that can lead to increases in food intake and adiposity that are both consistent with an obese phenotype (Figure 1). The actions of both peripheral and hypothalamic signals that interact to modulate feeding behavior are disrupted by glucocorticoids. Exposure to stressors and elevation in glucocorticoids lead to concomitant increases in peripheral levels of ghrelin [103-105]. Ghrelin is secreted from the stomach and typically acts as an orexigenic peptide [106] via facilitating the hypothalamic actions of neuropeptide Y (NPY) and agouti-related protein (AGRP) [107]. Glucocorticoid action following exposure to stress can also directly stimulate NPY release from sympathetic nerves that acts to increase both NPY and NPY receptor expression on adipocytes whose actions facilitate fat growth [108]. This mechanism of fat storage is dependent on increased lipoprotein lipase (LPL) activity within visceral fat [4], and acts as a feed-forward loop to augment the accumulation of abdominal fat [108] characteristic of obesity [4]. This 
glucocorticoid-induced increase in body fat also results in the augmented secretion of adipokines, such as interleukin-6 (IL-6) and tumor necrosis factor a (TNFa), from adipocytes that are involved in the development of insulin resistance [109].

Glucocorticoids also potentiate the orexigenic actions of hypothalamic melanin-concentrating hormone $(\mathrm{MCH})$ [110] and weaken the actions of anorectic signals. For instance, excess glucocorticoids can lead to insulin resistance indirectly by increasing glucose production from the liver and decreasing glucose uptake by skeletal muscle [111]. The overall increase in peripheral glucose levels leads to augmented insulin release from the pancreas that with time manifests as insulin resistance [111]. Hyperinsulinemia is a cardinal phenotype of obesity that can also lead to dysregulation of leptin signaling in adipocytes that normally acts to suppress secretion of insulin from the pancreas [112]. Leptin signaling from adipocytes serves as peripheral satiety signal and chronic elevated levels of glucocorticoids can lead to hyperleptinemia as well as to leptin resistance [113], both phenotypes associated with obesity [114].

The arcuate nucleus of the hypothalamus as well as the paraventricular nucleus (PVN) express high levels of glucocorticoid receptors (GRs) $[115,116]$ by which cortisol and corticosterone mediate central effects of stress exposure on food intake [117]. The cellular mechanisms by which glucocorticoids act via GRs to impair insulin and glucose homeostasis is reviewed elsewhere [118]. However, the actions of peripheral GRs are also necessary for the development of stress-induced obesity, as mice lacking adipocyte GR expression are resistant to developing obesity in a CDD environment [119]. Thus, glucocorticoid resistance coincident with hypercortisolemic conditions, such as obesity and depression, may further exacerbate glucocorticoid mediated increases in body fat and release of inflammatory adipokines.

In contrast to the actions of glucocorticoids on food intake and metabolism, E2 attenuates food intake and prevents the development of obesity and insulin resistance (Figure 1) [120]. Studies in rodents [121], non-human primates and women have all showed that E2 is anorectic and increases energy expenditure and activity levels. More specifically, E2 suppresses lipogenesis in adipocytes by decreasing the activity of LPL, increases lipolysis via stimulation of hormone-sensitive lipase (HSL) [122], and 
suppresses glucose production in the liver [123]. Indeed, when E2 levels are low, visceral fat accumulates in females [124], via the actions of E2 receptors (ERs) expressed in adipose tissue [125]. Both estrogen receptors (ER) $\alpha(E R \alpha)$ and $\beta(E R \beta)$ are expressed in human visceral adipose tissue [126], and genetic polymorphisms and deletions of the ERs are associated with increased risk for obesity in humans [127] and in rodents [128]. Not only does E2 also facilitate insulin-induced update of glucose in skeletal muscle but also via both ER $\alpha$ and ER $\beta$ mechanisms in the pancreas that facilitate the regulation of insulin synthesis and release (reviewed in [122]).

Importantly, E2 also acts to facilitate the actions of anorexigenic signals and attenuate the actions of orexigenic molecules. More specifically, expression and secretion of hypothalamic NPY is attenuated by $\mathrm{E} 2[129,130]$. The actions of ghrelin and $\mathrm{MCH}$ to stimulate food intake are similarly decreased in with E2 replacement in ovariectomized rodents $[131,132]$. Other translational rodent research indicates that E2 also increases the anorectic actions of leptin while concurrently increasing insulin sensitivity via augmenting expression of insulin receptors in adipose tissue, and promoting the accumulation of subcutaneous over visceral fat mass [133]. Leptin receptors are co-localized with ERs in the arcuate nucleus of the hypothalamus indicating a direct mechanism by which E2 increases leptin sensitivity [134]. More recently it was shown in female rodents fed a CDD that E2 decreases diet-induced hypothalamic neurogenesis of leptin-sensitive neurons in the arcuate [135]. A similar study showed that E2 administration in ovariectomized mice normalizes the decreased insulin sensitivity associated with four weeks of HFD exposure [136]. E2 replacement in ovariectomized mice has also been shown to decrease the expression of TNFa, LPL, and fatty acid synthase in adipocytes [137], all effects consistent with decreased fat accumulation and food intake.

Taken together, these data suggest that the effects of E2 on food intake and metabolism are typically opposite those of glucocorticoids on these same central and peripheral systems (Figure 1). However, under conditions of chronic stress exposure and concomitant LHPA dysregulation, the beneficial effects of E2 on these systems may be lost or even reversed, such that the actions of E2 may facilitate those of glucocorticoids. One mechanism by this may occur is via changes in sensitivity and expression of 
central and peripheral ERs [122]. ERa and ER $\beta$ are expressed in the hypothalamus of rodents, with ERa expressed predominantly in the arcuate nucleus and ER $\beta$ expressed predominantly in the PVN [138]. The direct role of ERs on the anorectic effects of E2 are highlighted by data showing that the selective knock down or ERa in the hypothalamus of mice increases hyperphagia and fat accumulation [139], and that the anorectic effects of E2 are diminished in the presence of ERß oligodeoxynucleotides [140]. Importantly, corticosterone treatment in rodents increases ER $\beta$ in the PVN [141], suggesting that exposure to chronic stressors and conditions of hypercortisolemia can site-specifically alter ER expression. In humans suffering from major depressive and bipolar disorder, ER $\alpha$ co-localization with $\mathrm{CRH}$ in the PVN that is normally very low to nonexistent, is increased [142]. While these data suggest that stress may alter the expression, and thus the function, of ERs to increase risk for obesogenic physiology and behavior in females, more studies are necessary to further test this hypothesis.

\section{Alterations in Reward Pathways.}

Another mechanism by which chronic stressor exposure may increase risk for obesity in women is via modulation of reward circuitry and neurochemistry, as mesolimbic dopamine signaling is critical to the rewarding aspects of food intake [143]. The underlying mechanism by which stress exposure influences reward pathways revolves around signals from the stress axis, including $\mathrm{CRH}$, that decrease dopamine (DA) levels within prefrontal regions and increase DA in the nucleus accumbens [144] by acting upon dopaminergic neurons in mesocortical regions [145-147]. The effects of CRH on DA levels can also decrease mesolimbic dopamine 2 receptor (D2R) levels [148]. Decreases of D2R have been linked to anhedonia and increased risk for developing an addictive phenotype [149-151], including compulsive eating [152]. Socially subordinate female monkeys also show reduced levels D2R binding potential (BP) assessed by positron emission tomography (PET) $[85,86,153,154]$ that are coincident with decreased estimates of central DA release [86, 155] and increased rates of cocaine self-administration [154].

A reduction in D2R levels is characteristic to both psychostimulant abuse $[156,157]$ and dietinduced obesity [158-161]. It has been proposed that the attenuation of striatal D2R binding may increase 
susceptibility to drug abuse, as this hypodopaminergic state is thought to reflect a reward deficiency syndrome [162]. The notion that stress-induced emotional eating is a form of addiction is not new [163], as this form of eating represents an attempt to stimulate a hypodopaminergic reward system by intake of CCDs [164-166]. Importantly, women are at higher risk for cocaine addiction [167], just as they are more vulnerable to increased caloric intake and obesity $[21,71]$. Translational data from rodent models indicate that E2 stimulates striatal DA release $[168,169]$ and transiently decreases D2R availability [170-172]. This effect of E2 on the dopaminergic system in females is linked to an increased propensity to self-administer cocaine $[173,174]$. While these data from translational rodent work suggest that E2 may increase motivation to ingest CDDs similar to its enhancing motivational effects of E2 on cocaine abuse in women, it remains to be determined whether exposure to chronic stress exacerbates the effects of E2 on reward pathways to drive stress-induced intake of CDDs in females.

\section{Conclusions}

In summary, the increased risk for obesity in females may be due to chronic stress-induced alterations in the behavioral and physiological effects of E2. However, to further delineate the mechanisms by which women are more vulnerable to the development of obesity, translational and clinical research must be expanded to systematically address the effects of sex and gonadal hormones in the etiology of stress-induced disorders [175]. The value of such translational animal work is exemplified by the body of work summarized in Table 1 describing the effects of social subordination on health-related phenotypes in female macaques. Taken together, these data from female macaques suggest that chronic psychosocial stress exposure alters sensitivity to E2 thereby increasing risk for adverse health outcomes in females. It is also important to study these questions throughout development and adulthood, as stress-induced emotional eating occurs in girls [176-178], and results in higher rates of obesity [179-182], particularly in girls [176-178]. Accounting for sex and gonadal hormones in our examination of stress axis function in obesity will offer clarity on the complex relationship, as well as yield novel targets for alleviating the adverse consequences of obesity specifically in females. 


\section{Acknowledgements}

I would like to thank Jennifer Whitley, Angela Tripp, Brandon Hughes, Shannon Bounar, Jodi Godfrey, Christine Marsteller, Jonathon Lowe, Patrick Ulam, Rebecca Herman, Robert Johnston and Gregory Henry for their expert technical assistance in conducting the feeding studies in non-human primates summarized in the current review. I also would like to thank Drs. Mark Wilson, Donna Toufexis, Zachary Johnson, Carla Moore and Rickey Gillespie for helping shape my understanding of the relationship between stressor exposure, emotional eating, and risk for obesity in women. These studies would not have been possible without support from NIH grants HD46501, MH081816, RR00165, and F31MH085445 (VM). Further support was provided by the Center for Behavioral Neuroscience through the STC Program of the National Science Foundation IBN-9876754. 
Table 1. Summary of phenotypes associated with social subordination in female rhesus macaques, including altered behavioral and physiological sensitivity to estradiol (E2). Significant differences in summarized phenotypes between dominant (Dom) and subordinate (Sub).

\begin{tabular}{|c|c|c|}
\hline Phenotype & Description & References \\
\hline \multicolumn{3}{|l|}{ LHPA Axis } \\
\hline Glucocorticoid negative feedback & Dom > Sub & [84-86] \\
\hline Basal cortisol levels & Sub > Dom & {$[84,85]$} \\
\hline Adrenal Size & Sub > Dom & {$[86]$} \\
\hline \multicolumn{3}{|l|}{ HPG Axis } \\
\hline Reproductive deficits & Sub > Dom & {$[95,96]$} \\
\hline E2 negative feedback of HPG axis & Sub > Dom & [94] \\
\hline Oxytocin levels & Dom $>$ Sub & [93] \\
\hline \multicolumn{3}{|l|}{ Food intake } \\
\hline Standard LCD & Sub Dom & {$[35,73]$} \\
\hline Choice Condition & Sub > Dom & {$[35,73,83]$} \\
\hline $\begin{array}{r}\text { Anorectic effects of E2 during choice } \\
\text { condition }\end{array}$ & Sub < Dom & [98] \\
\hline \multicolumn{3}{|l|}{$\begin{array}{l}\text { Metabolic Characteristics in LCD } \\
\text { Condition }\end{array}$} \\
\hline Body Weight & Dom > Sub & [80] \\
\hline Body Fat & Dom $>$ Sub & [80] \\
\hline Bone Mass & Dom > Sub & [80] \\
\hline Leptin levels & Dom $>$ Sub & [80] \\
\hline \multicolumn{3}{|l|}{ Inflammation } \\
\hline Inflammatory gene expression & Sub > Dom & [81] \\
\hline \multicolumn{3}{|l|}{ Behavior } \\
\hline Aggression Emitted & Sub < Dom & {$[78,79]$} \\
\hline Submission Emitted & Sub > Dom & {$[80]$} \\
\hline Affiliation Received & Sub < Dom & [93] \\
\hline Anxiolytic effects of E2 & Sub < Dom & [93] \\
\hline
\end{tabular}


Figure 1. Opposing actions of glucocorticoids (cortisol) and estradiol on regulators of metabolism and food intake. Exposure to chronic stress and dysregulation of the LHPA axis may result in the loss and/or reversal of the protective effects of E2 on metabolism and food intake. 


\section{References}

[1] Ogden, C. L., Carroll, M. D., Fryar, C. D., Flegal, K. M. Prevalence of obesity among adults and youth: United States, 2011-2014. NHCS data brief. Hyattsville, MD: National Center for Health Statistics; 2015.

[2] Flegal, K. M., Carroll, M. D., Ogden, C. L., Curtin, L. R. Prevalence and trends in obesity among US adults, 1999-2008. JAMA. 2010,303:235-41.

[3] Hill, J. O. Understanding and addressing the epidemic of obesity: an energy balance perspective. Endocrine reviews. 2006,27:750-61.

[4] Bjorntorp, P. Do stress reactions cause abdominal obesity and comorbidities? Obes Rev. 2001,2:73-86.

[5] Flegal, K. M. Epidemiologic aspects of overweight and obesity in the United States. Physiology \& behavior. 2005,86:599-602.

[6] Dallman, M. F., Pecoraro, N. C., la Fleur, S. E. Chronic stress and comfort foods: self-medication and abdominal obesity. Brain Behav Immun. 2005,19:275-80.

[7] Dallman, M. F., Pecoraro, N., Akana, S. F., La Fleur, S. E., Gomez, F., Houshyar, H., et al. Chronic stress and obesity: a new view of "comfort food". Proceedings of the National Academy of Sciences of the United States of America. 2003,100:11696-701.

[8] Pasquali, R., Ambrosi, B., Armanini, D., Cavagnini, F., Uberti, E. D., Del Rio, G., et al. Cortisol and ACTH response to oral dexamethasone in obesity and effects of sex, body fat distribution, and dexamethasone concentrations: a dose-response study. The Journal of clinical endocrinology and metabolism. 2002,87:166-75.

[9] Epel, E. S., McEwen, B., Seeman, T., Matthews, K., Castellazzo, G., Brownell, K. D., et al. Stress and body shape: stress-induced cortisol secretion is consistently greater among women with central fat.

Psychosom Med. 2000,62:623-32.

[10] Duclos, M., Marquez Pereira, P., Barat, P., Gatta, B., Roger, P. Increased cortisol bioavailability, abdominal obesity, and the metabolic syndrome in obese women. Obesity research. 2005,13:1157-66. [11] Walker, B. R., Soderberg, S., Lindahl, B., Olsson, T. Independent effects of obesity and cortisol in predicting cardiovascular risk factors in men and women. J Intern Med. 2000,247:198-204.

[12] Sulentic, P., Morris, D. G., Grossman, A. Cushing's Disease. 2000.

[13] Karatsoreos, I. N., Bhagat, S. M., Bowles, N. P., Weil, Z. M., Pfaff, D. W., McEwen, B. S. Endocrine and physiological changes in response to chronic corticosterone: a potential model of the metabolic syndrome in mouse. Endocrinology. 2010,151:2117-27.

[14] Auvinen, H. E., Coomans, C. P., Boon, M. R., Romijn, J. A., Biermasz, N. R., Meijer, O. C., et al. Glucocorticoid excess induces long-lasting changes in body composition in male C57Bl/6J mice only with high-fat diet. Physiol Rep. 2013,1:e00103.

[15] Rebuffe-Scrive, M., Walsh, U. A., McEwen, B., Rodin, J. Effect of chronic stress and exogenous glucocorticoids on regional fat distribution and metabolism. Physiology \& behavior. 1992,52:583-90.

[16] George, S. A., Khan, S., Briggs, H., Abelson, J. L. CRH-stimulated cortisol release and food intake in healthy, non-obese adults. Psychoneuroendocrinology. 2010,35:607-12.

[17] Wung, P. K., Anderson, T., Fontaine, K. R., Hoffman, G. S., Specks, U., Merkel, P. A., et al. Effects of glucocorticoids on weight change during the treatment of Wegener's granulomatosis. Arthritis Rheum. 2008,59:746-53.

[18] Harris, R. B. Chronic and acute effects of stress on energy balance: are there appropriate animal models? American journal of physiology. 2015,308:R250-65.

[19] Pasquali, R., Vicennati, V., Cacciari, M., Pagotto, U. The hypothalamic-pituitary-adrenal axis activity in obesity and the metabolic syndrome. Annals of the New York Academy of Sciences. 2006,1083:111-28.

[20] Payette, C., Blackburn, P., Lamarche, B., Tremblay, A., Bergeron, J., Lemieux, I., et al. Sex differences in postprandial plasma tumor necrosis factor-alpha, interleukin-6, and C-reactive protein concentrations. Metabolism. 2009,58:1593-601.

[21] Zellner, D. A., Loaiza, S., Gonzalez, Z., Pita, J., Morales, J., Pecora, D., et al. Food selection changes under stress. Physiology \& behavior. 2006,87:789-93. 
[22] Zellner, D. A., Saito, S., Gonzalez, J. The effect of stress on men's food selection. Appetite. 2007,49:696-9.

[23] Weissman, M. M., Olfson, M. Depression in women: implications for health care research. Science (New York, N.Y. 1995,269:799-801.

[24] Barry, D., Pietrzak, R. H., Petry, N. M. Gender differences in associations between body mass index and DSM-IV mood and anxiety disorders: results from the National Epidemiologic Survey on Alcohol and Related Conditions. Annals of epidemiology. 2008,18:458-66.

[25] Jones, L. E., Carney, C. P. Increased risk for metabolic syndrome in persons seeking care for mental disorders. Ann Clin Psychiatry. 2006,18:149-55.

[26] Wurtman, J. J. Depression and weight gain: the serotonin connection. Journal of affective disorders. 1993,29:183-92.

[27] Wurtman, R. J., Wurtman, J. J. Brain serotonin, carbohydrate-craving, obesity and depression. Obesity research. 1995,3 Suppl 4:477S-80S.

[28] Chrousos, G. P., Gold, P. W. The concepts of stress and stress system disorders. Overview of physical and behavioral homeostasis. Jama. 1992,267:1244-52.

[29] McEwen, B. S. Stress, adaptation, and disease. Allostasis and allostatic load. Annals of the New York Academy of Sciences. 1998,840:33-44.

[30] Marmot, M. Health in an unequal world: social circumstances, biology and disease. Clin Med. 2006,6:559-72.

[31] Akana, S. F., Hanson, E. S., Horsley, C. J., Strack, A. M., Bhatnagar, S., Bradbury, M. J., et al. Clamped Corticosterone (B) Reveals the Effect of Endogenous B on Both Facilitated Responsivity to Acute Restraint and Metabolic Responses to Chronic Stress. Stress (Amsterdam, Netherlands). 1996,1:33-49. [32] Bhatnagar, S., Meaney, M. J. Hypothalamic-pituitary-adrenal function in chronic intermittently coldstressed neonatally handled and non handled rats. Journal of neuroendocrinology. 1995,7:97-108. [33] Ottenweller, J. E., Natelson, B. H., Pitman, D. L., Drastal, S. D. Adrenocortical and behavioral responses to repeated stressors: toward an animal model of chronic stress and stress-related mental illness. Biological psychiatry. 1989,26:829-41.

[34] Donner, N. C., Montoya, C. D., Lukkes, J. L., Lowry, C. A. Chronic non-invasive corticosterone administration abolishes the diurnal pattern of tph2 expression. Psychoneuroendocrinology. 2011. [35] Arce, M., Michopoulos, V., Shepard, K. N., Ha, Q. C., Wilson, M. E. Diet choice, cortisol reactivity, and emotional feeding in socially housed rhesus monkeys. Physiology \& behavior. 2010,101:446-55. [36] O'Connor, D. B., Hendrickx, H., Dadd, T., Elliman, T. D., Willis, T. A., Talbot, D., et al. Cortisol awakening rise in middle-aged women in relation to psychological stress. Psychoneuroendocrinology. 2009,34:1486-94.

[37] Fries, E., Dettenborn, L., Kirschbaum, C. The cortisol awakening response (CAR): facts and future directions. Int J Psychophysiol. 2009,72:67-73.

[38] Kaplan, J. R., Adams, M. R., Clarkson, T. B., Koritnik, D. R. Psychosocial influences on female 'protection' among cynomolgus macaques. Atherosclerosis. 1984,53:283-95.

[39] Akana, S. F., Dallman, M. F., Bradbury, M. J., Scribner, K. A., Strack, A. M., Walker, C. D. Feedback and facilitation in the adrenocortical system: unmasking facilitation by partial inhibition of the glucocorticoid response to prior stress. Endocrinology. 1992,131:57-68.

[40] Strausbaugh, H. J., Dallman, M. F., Levine, J. D. Repeated, but not acute, stress suppresses inflammatory plasma extravasation. Proceedings of the National Academy of Sciences of the United States of America. 1999,96:14629-34.

[41] Dallman, M. F., Akana, S. F., Strack, A. M., Scribner, K. S., Pecoraro, N., La Fleur, S. E., et al. Chronic stress-induced effects of corticosterone on brain: direct and indirect. Annals of the New York Academy of Sciences. 2004,1018:141-50.

[42] Pecoraro, N., Reyes, F., Gomez, F., Bhargava, A., Dallman, M. F. Chronic stress promotes palatable feeding, which reduces signs of stress: Feedforward and feedback effects of chronic stress. Endocrinology. 2004,145:3754-62. 
[43] Foster, M. T., Warne, J. P., Ginsberg, A. B., Horneman, H. F., Pecoraro, N. C., Akana, S. F., et al. Palatable foods, stress, and energy stores sculpt corticotropin-releasing factor, adrenocorticotropin, and corticosterone concentrations after restraint. Endocrinology. 2009,150:2325-33.

[44] Dallman, M. F., La Fleur, S. E., Pecoraro, N. C., Gomez, F., Houshyar, H., Akana, S. F. Minireview: glucocorticoids--food intake, abdominal obesity, and wealthy nations in 2004. Endocrinology.

2004,145:2633-8.

[45] Bhatnagar, S., Dallman, M. Neuroanatomical basis for facilitation of hypothalamic-pituitary-adrenal responses to a novel stressor after chronic stress. Neuroscience. 1998,84:1025-39.

[46] Bhatnagar, S., Viau, V., Chu, A., Soriano, L., Meijer, O. C., Dallman, M. F. A cholecystokinin-mediated pathway to the paraventricular thalamus is recruited in chronically stressed rats and regulates hypothalamic-pituitary-adrenal function. J Neurosci. 2000,20:5564-73.

[47] Akana, S. F., Dallman, M. F. Chronic cold in adrenalectomized, corticosterone (B)-treated rats: facilitated corticotropin responses to acute restraint emerge as B increases. Endocrinology.

1997,138:3249-58.

[48] Armario, A. The hypothalamic-pituitary-adrenal axis: what can it tell us about stressors? CNS Neurol Disord Drug Targets. 2006,5:485-501.

[49] Jaferi, A., Bhatnagar, S. Corticosterone can act at the posterior paraventricular thalamus to inhibit hypothalamic-pituitary-adrenal activity in animals that habituate to repeated stress. Endocrinology. 2006,147:4917-30.

[50] Bhatnagar, S., Dallman, M. F., Roderick, R. E., Basbaum, A. I., Taylor, B. K. The effects of prior chronic stress on cardiovascular responses to acute restraint and formalin injection. Brain research. 1998,797:313-20.

[51] Bhatnagar, S., Vining, C. Facilitation of hypothalamic-pituitary-adrenal responses to novel stress following repeated social stress using the resident/intruder paradigm. Hormones and behavior. 2003,43:158-65.

[52] Bhatnagar, S., Vining, C., Iyer, V., Kinni, V. Changes in hypothalamic-pituitary-adrenal function, body temperature, body weight and food intake with repeated social stress exposure in rats. Journal of neuroendocrinology. 2006,18:13-24.

[53] Herman, J. P., Adams, D., Prewitt, C. Regulatory changes in neuroendocrine stress-integrative circuitry produced by a variable stress paradigm. Neuroendocrinology. 1995,61:180-90.

[54] McGuire, J., Herman, J. P., Horn, P. S., Sallee, F. R., Sah, R. Enhanced fear recall and emotional arousal in rats recovering from chronic variable stress. Physiology \& behavior. 2010,101:474-82.

[55] Dalla, C., Antoniou, K., Drossopoulou, G., Xagoraris, M., Kokras, N., Sfikakis, A., et al. Chronic mild stress impact: are females more vulnerable? Neuroscience. 2005,135:703-14.

[56] Flak, J. N., Ostrander, M. M., Tasker, J. G., Herman, J. P. Chronic stress-induced neurotransmitter plasticity in the PVN. The Journal of comparative neurology. 2009,517:156-65.

[57] Solomon, M. B., Jankord, R., Flak, J. N., Herman, J. P. Chronic stress, energy balance and adiposity in female rats. Physiology \& behavior. 2011,102:84-90.

[58] la Fleur, S. E., van Rozen, A. J., Luijendijk, M. C., Groeneweg, F., Adan, R. A. A free-choice high-fat high-sugar diet induces changes in arcuate neuropeptide expression that support hyperphagia. Int $\mathrm{J}$ Obes (Lond). 2010,34:537-46.

[59] Raab, A., Dantzer, R., Michaud, B., Mormede, P., Taghzouti, K., Simon, H., Le Moal, M. Behavioral, physiological and immunological consequences of social status and aggression in chronically coexisting resident-intruder dyads of male rats. Physiol. Behav. 1986,36:223-8.

[60] Razzoli, M., Carboni, L., Arban, R. Alterations of behavioral and endocrinological reactivity induced by 3 brief social defeats in rats: relevance to human psychopathology. Psychoneuroendocrinology.

2009,34:1405-16.

[61] Stefanski, V. Social stress in laboratory rats: hormonal responses and immune cell distribution. Psychoneuroendocrinology. 2000,25:389-406.

[62] Foster, M. T., Solomon, M. B., Huhman, K. L., Bartness, T. J. Social defeat increases food intake, body mass, and adiposity in Syrian hamsters. American journal of physiology. 2006,290:R1284-93. 
[63] Solomon, M. B., Foster, M. T., Bartness, T. J., Huhman, K. L. Social defeat and footshock increase body mass and adiposity in male Syrian hamsters. American journal of physiology. 2007,292:R283-90. [64] Scott, K. A., Melhorn, S. J., Sakai, R. R. Effects of Chronic Social Stress on Obesity. Curr Obes Rep. 2012,1:16-25.

[65] Blanchard, D. C., Spencer, R. L., Weiss, S. M., Blanchard, R. J., McEwen, B., Sakai, R. R. Visible burrow system as a model of chronic social stress: behavioral and neuroendocrine correlates.

Psychoneuroendocrinology. 1995,20:117-34.

[66] Blanchard, D. C., Sakai, R. R., McEwen, B., Weiss, S. M., Blanchard, R. J. Subordination stress: behavioral, brain, and neuroendocrine correlates. Behavioural brain research. 1993,58:113-21.

[67] Tamashiro, K. L., Nguyen, M. M., Fujikawa, T., Xu, T., Yun Ma, L., Woods, S. C., et al. Metabolic and endocrine consequences of social stress in a visible burrow system. Physiology \& behavior. 2004,80:68393.

[68] Choi, D. C., Nguyen, M. M., Tamashiro, K. L., Ma, L. Y., Sakai, R. R., Herman, J. P. Chronic social stress in the visible burrow system modulates stress-related gene expression in the bed nucleus of the stria terminalis. Physiology \& behavior. 2006,89:301-10.

[69] Tamashiro, K. L., Nguyen, M. M., Ostrander, M. M., Gardner, S. R., Ma, L. Y., Woods, S. C., et al. Social stress and recovery: implications for body weight and body composition. American journal of physiology. 2007,293:R1864-74.

[70] Carvalho-Netto, E. F., Myers, B., Jones, K., Solomon, M. B., Herman, J. P. Sex differences in synaptic plasticity in stress-responsive brain regions following chronic variable stress. Physiology \& behavior. 2011,104:242-7.

[71] Grunberg, N. E., Straub, R. O. The role of gender and taste class in the effects of stress on eating. Health Psychol. 1992,11:97-100.

[72] Epel, E., Lapidus, R., McEwen, B., Brownell, K. Stress may add bite to appetite in women: a laboratory study of stress-induced cortisol and eating behavior. Psychoneuroendocrinology. 2001,26:37-49.

[73] Michopoulos, V., Toufexis, D., Wilson, M. E. Social stress interacts with diet history to promote emotional feeding in females. Psychoneuroendocrinology. 2012,37:1479-90.

[74] Pasquali, R., Cantobelli, S., Casimirri, F., Capelli, M., Bortoluzzi, L., Flamia, R., et al. The hypothalamic-pituitary-adrenal axis in obese women with different patterns of body fat distribution. The Journal of clinical endocrinology and metabolism. 1993,77:341-6.

[75] Vicennati, V., Pasqui, F., Cavazza, C., Pagotto, U., Pasquali, R. Stress-related development of obesity and cortisol in women. Obesity (Silver Spring). 2009,17:1678-83.

[76] Vicennati, V., Pasqui, F., Cavazza, C., Garelli, S., Casadio, E., di Dalmazi, G., et al. Cortisol, energy intake, and food frequency in overweight/obese women. Nutrition (Burbank, Los Angeles County, Calif. 2011,27:677-80.

[77] Sapolsky, R. M. The influence of social hierarchy on primate health. Science (New York, N.Y. 2005,308:648-52.

[78] Bernstein, I. S. Dominance, aggression and reproduction in primate societies. J Theor Biol. 1976,60:459-72.

[79] Bernstein, I. S., Gordon, T. P. The function of aggression in primate societies. Am Sci. 1974,62:30411.

[80] Michopoulos, V., Higgins, M., Toufexis, D., Wilson, M. E. Social subordination produces distinct stressrelated phenotypes in female rhesus monkeys. Psychoneuroendocrinology. 2012,37:1071-85.

[81] Tung, J., Barreiro, L. B., Johnson, Z. P., Hansen, K. D., Michopoulos, V., Toufexis, D., et al. Social environment is associated with gene regulatory variation in the rhesus macaque immune system.

Proceedings of the National Academy of Sciences of the United States of America. 2012,109:6490-5. [82] Michopoulos, V., Reding, K. M., Wilson, M. E., Toufexis, D. Social subordination impairs hypothalamicpituitary-adrenal function in female rhesus monkeys. Hormones and behavior. 2012,62:389-99.

[83] Wilson, M. E., Fisher, J., Fischer, A., Lee, V., Harris, R. B., Bartness, T. J. Quantifying food intake in socially housed monkeys: social status effects on caloric consumption. Physiology \& behavior.

2008,94:586-94. 
[84] Wilson, M. E., Pazol, K., Legendre, A., Fisher, J., Chikazawa, K. Gonadal steroid modulation of the limbic - hypothalamic - pituitary - adrenal (LHPA) axis is influenced by social status in female rhesus monkeys. Endocrine. 2005,26.

[85] Shively, C. A., Grant, K. A., Ehrenkaufer, R. L., Mach, R. H., Nader, M. A. Social stress, depression, and brain dopamine in female cynomolgus monkeys. Annals of the New York Academy of Sciences. 1997,807:574-7.

[86] Shively, C. A. Social subordination stress, behavior, and central monoaminergic function in female cynomolgus monkeys. Biological psychiatry. 1998,44:882-91.

[87] Shively, C., Kaplan, J. Effects of social factors on adrenal weight and related physiology of Macaca fascicularis. Physiology \& behavior. 1984,33:777-82.

[88] Moore, C. J., Lowe, J., Michopoulos, V., Ulam, P., Toufexis, D., Wilson, M. E., et al. Small changes in meal patterns lead to significant changes in total caloric intake. Effects of diet and social status on food intake in female rhesus monkeys. Appetite. 2013,62:60-9.

[89] Kamara, K., Eskay, R., Castonguay, T. High-fat diets and stress responsivity. Physiology \& behavior. 1998,64:1-6.

[90] Tannenbaum, B. M., Brindley, D. N., Tannenbaum, G. S., Dallman, M. F., McArthur, M. D., Meaney, M. J. High-fat feeding alters both basal and stress-induced hypothalamic-pituitary-adrenal activity in the rat.

The American journal of physiology. 1997,273:E1168-77.

[91] McNeilly, A. D., Stewart, C. A., Sutherland, C., Balfour, D. J. High fat feeding is associated with stimulation of the hypothalamic-pituitary-adrenal axis and reduced anxiety in the rat.

Psychoneuroendocrinology. 2015,52:272-80.

[92] Moore, C. J., Johnson, Z. P., Higgins, M., Toufexis, D., Wilson, M. E. Antagonism of corticotrophinreleasing factor type 1 receptors attenuates caloric intake of free feeding subordinate female rhesus monkeys in a rich dietary environment. Journal of neuroendocrinology. 2015,27:33-43.

[93] Michopoulos, V., Checchi, M., Sharpe, D., Wilson, M. E. Estradiol effects on behavior and serum oxytocin are modified by social status and polymorphisms in the serotonin transporter gene in female rhesus monkeys. Hormones and behavior. 2011,59:528-35.

[94] Michopoulos, V., Berga, S. L., Kaplan, J. R., Wilson, M. E. Social subordination and polymorphisms in the gene encoding the serotonin transporter enhance estradiol inhibition of luteinizing hormone secretion in female rhesus monkeys. Biology of reproduction. 2009,81:1154-63.

[95] Adams, M. R., Kaplan, J. R., Koritnik, D. R. Psychosocial influences on ovarian endocrine and ovulatory function in Macaca fascicularis. Physiology \& behavior. 1985,35:935-40.

[96] Walker, M. L., Gordon, T. P., Wilson, M. E. Menstrual cycle characteristics of seasonally breeding rhesus monkeys. Biology of reproduction. 1983,29:841-8.

[97] Geary, N. Estradiol and appetite. Appetite. 2000,35:273-4.

[98] Johnson, Z. P., Lowe, J., Michopoulos, V., Moore, C. J., Wilson, M. E., Toufexis, D. Oestradiol differentially influences feeding behaviour depending on diet composition in female rhesus monkeys. Journal of neuroendocrinology. 2013,25:729-41.

[99] Fong, A. K., Kretsch, M. J. Changes in dietary intake, urinary nitrogen, and urinary volume across the menstrual cycle. Am J Clin Nutr. 1993,57:43-6.

[100] Gong, E. J., Garrel, D., Calloway, D. H. Menstrual cycle and voluntary food intake. Am J Clin Nutr. 1989,49:252-8.

[101] Johnson, W. G., Corrigan, S. A., Lemmon, C. R., Bergeron, K. B., Crusco, A. H. Energy regulation over the menstrual cycle. Physiology \& behavior. 1994,56:523-7.

[102] Lissner, L., Stevens, J., Levitsky, D. A., Rasmussen, K. M., Strupp, B. J. Variation in energy intake during the menstrual cycle: implications for food-intake research. Am J Clin Nutr. 1988,48:956-62.

[103] Ochi, M., Tominaga, K., Tanaka, F., Tanigawa, T., Shiba, M., Watanabe, T., et al. Effect of chronic stress on gastric emptying and plasma ghrelin levels in rats. Life sciences. 2008,82:862-8.

[104] Kristensen, K., Pedersen, S. B., Richelsen, B. Regulation of leptin by steroid hormones in rat adipose tissue. Biochemical and biophysical research communications. 1999,259:624-30. 
[105] Kristenssson, E., Sundqvist, M., Astin, M., Kjerling, M., Mattsson, H., Dornonville de la Cour, C., et al. Acute psychological stress raises plasma ghrelin in the rat. Regulatory peptides. 2006,134:114-7.

[106] Kojima, M., Hosoda, H., Date, Y., Nakazato, M., Matsuo, H., Kangawa, K. Ghrelin is a growthhormone-releasing acylated peptide from stomach. Nature. 1999,402:656-60.

[107] Asakawa, A., Inui, A., Kaga, T., Yuzuriha, H., Nagata, T., Fujimiya, M., et al. A role of ghrelin in neuroendocrine and behavioral responses to stress in mice. Neuroendocrinology. 2001,74:143-7.

[108] Kuo, L. E., Kitlinska, J. B., Tilan, J. U., Li, L., Baker, S. B., Johnson, M. D., et al. Neuropeptide Y acts directly in the periphery on fat tissue and mediates stress-induced obesity and metabolic syndrome. Nat Med. 2007.

[109] Smitka, K., Maresova, D. Adipose Tissue as an Endocrine Organ: An Update on Pro-inflammatory and Anti-inflammatory Microenvironment. Prague Med Rep. 2015,116:87-111.

[110] Drazen, D. L., Coolen, L. M., Strader, A. D., Wortman, M. D., Woods, S. C., Seeley, R. J. Differential effects of adrenalectomy on melanin-concentrating hormone and orexin A. Endocrinology. 2004,145:340412.

[111] Kuo, T., McQueen, A., Chen, T. C., Wang, J. C. Regulation of Glucose Homeostasis by Glucocorticoids. Advances in experimental medicine and biology. 2015,872:99-126.

[112] Kieffer, T. J., Heller, R. S., Leech, C. A., Holz, G. G., Habener, J. F. Leptin suppression of insulin secretion by the activation of ATP-sensitive K+ channels in pancreatic beta-cells. Diabetes. 1997,46:108793.

[113] Newcomer, J. W., Selke, G., Melson, A. K., Gross, J., Vogler, G. P., Dagogo-Jack, S. Dosedependent cortisol-induced increases in plasma leptin concentration in healthy humans. Archives of general psychiatry. 1998,55:995-1000.

[114] Farr, O. M., Gavrieli, A., Mantzoros, C. S. Leptin applications in 2015: what have we learned about leptin and obesity? Curr Opin Endocrinol Diabetes Obes. 2015,22:353-9.

[115] Morimoto, M., Morita, N., Ozawa, H., Yokoyama, K., Kawata, M. Distribution of glucocorticoid receptor immunoreactivity and mRNA in the rat brain: an immunohistochemical and in situ hybridization study. Neurosci Res. 1996,26:235-69.

[116] Sanchez, M. M., Young, L. J., Plotsky, P. M., Insel, T. R. Distribution of corticosteroid receptors in the rhesus brain: relative absence of glucocorticoid receptors in the hippocampal formation. J Neurosci. 2000,20:4657-68.

[117] Yi, C. X., Foppen, E., Abplanalp, W., Gao, Y., Alkemade, A., la Fleur, S. E., et al. Glucocorticoid signaling in the arcuate nucleus modulates hepatic insulin sensitivity. Diabetes. 2012,61:339-45. [118] Patel, R., Williams-Dautovich, J., Cummins, C. L. Minireview: new molecular mediators of glucocorticoid receptor activity in metabolic tissues. Molecular endocrinology (Baltimore, Md. 2014,28:9991011.

[119] de Kloet, A. D., Krause, E. G., Solomon, M. B., Flak, J. N., Scott, K. A., Kim, D. H., et al. Adipocyte glucocorticoid receptors mediate fat-to-brain signaling. Psychoneuroendocrinology. 2015,56:110-9.

[120] Brown, L. M., Clegg, D. J. Central effects of estradiol in the regulation of food intake, body weight, and adiposity. The Journal of steroid biochemistry and molecular biology. 2010,122:65-73.

[121] Asarian, L., Geary, N. Modulation of appetite by gonadal steroid hormones. Philosophical transactions of the Royal Society of London. 2006,361:1251-63.

[122] Barros, R. P., Gustafsson, J. A. Estrogen receptors and the metabolic network. Cell Metab.

2011,14:289-99.

[123] Jelenik, T., Roden, M. How estrogens prevent from lipid-induced insulin resistance. Endocrinology. 2013,154:989-92.

[124] Bouchard, C., Despres, J. P., Mauriege, P. Genetic and nongenetic determinants of regional fat distribution. Endocrine reviews. 1993,14:72-93.

[125] Crandall, D. L., Busler, D. E., Novak, T. J., Weber, R. V., Kral, J. G. Identification of estrogen receptor beta RNA in human breast and abdominal subcutaneous adipose tissue. Biochemical and biophysical research communications. 1998,248:523-6. 
[126] Rodriguez-Cuenca, S., Monjo, M., Frontera, M., Gianotti, M., Proenza, A. M., Roca, P. Sex steroid receptor expression profile in brown adipose tissue. Effects of hormonal status. Cell Physiol Biochem. 2007,20:877-86.

[127] Casazza, K., Page, G. P., Fernandez, J. R. The association between the rs2234693 and rs9340799 estrogen receptor alpha gene polymorphisms and risk factors for cardiovascular disease: a review. Biol Res Nurs. 2010,12:84-97.

[128] Heine, P. A., Taylor, J. A., Iwamoto, G. A., Lubahn, D. B., Cooke, P. S. Increased adipose tissue in male and female estrogen receptor-alpha knockout mice. Proceedings of the National Academy of Sciences of the United States of America. 2000,97:12729-34.

[129] Bonavera, J. J., Dube, M. G., Kalra, P. S., Kalra, S. P. Anorectic effects of estrogen may be mediated by decreased neuropeptide-Y release in the hypothalamic paraventricular nucleus. Endocrinology. 1994,134:2367-70.

[130] Sar, M., Sahu, A., Crowley, W. R., Kalra, S. P. Localization of neuropeptide-Y immunoreactivity in estradiol-concentrating cells in the hypothalamus. Endocrinology. 1990,127:2752-6.

[131] Clegg, D. J., Brown, L. M., Zigman, J. M., Kemp, C. J., Strader, A. D., Benoit, S. C., et al. Estradioldependent decrease in the orexigenic potency of ghrelin in female rats. Diabetes. 2007,56:1051-8.

[132] Messina, M. M., Boersma, G., Overton, J. M., Eckel, L. A. Estradiol decreases the orexigenic effect of melanin-concentrating hormone in ovariectomized rats. Physiology \& behavior. 2006,88:523-8.

[133] Clegg, D. J., Brown, L. M., Woods, S. C., Benoit, S. C. Gonadal hormones determine sensitivity to central leptin and insulin. Diabetes. 2006,55:978-87.

[134] Diano, S., Kalra, S. P., Sakamoto, H., Horvath, T. L. Leptin receptors in estrogen receptor-containing neurons of the female rat hypothalamus. Brain research. 1998,812:256-9.

[135] Bless, E. P., Reddy, T., Acharya, K. D., Beltz, B. S., Tetel, M. J. Oestradiol and diet modulate energy homeostasis and hypothalamic neurogenesis in the adult female mouse. Journal of neuroendocrinology.

2014,26:805-16.

[136] Camporez, J. P., Jornayvaz, F. R., Lee, H. Y., Kanda, S., Guigni, B. A., Kahn, M., et al. Cellular mechanism by which estradiol protects female ovariectomized mice from high-fat diet-induced hepatic and muscle insulin resistance. Endocrinology. 2013,154:1021-8.

[137] Yonezawa, R., Wada, T., Matsumoto, N., Morita, M., Sawakawa, K., Ishii, Y., et al. Central versus peripheral impact of estradiol on the impaired glucose metabolism in ovariectomized mice on a high-fat diet. Am J Physiol Endocrinol Metab. 2012,303:E445-56.

[138] Shughrue, P. J., Lane, M. V., Merchenthaler, I. Comparative distribution of estrogen receptor-alpha and -beta mRNA in the rat central nervous system. The Journal of comparative neurology. 1997,388:50725.

[139] Musatov, S., Chen, W., Pfaff, D. W., Mobbs, C. V., Yang, X. J., Clegg, D. J., et al. Silencing of estrogen receptor alpha in the ventromedial nucleus of hypothalamus leads to metabolic syndrome. Proceedings of the National Academy of Sciences of the United States of America. 2007,104:2501-6. [140] Liang, Y. Q., Akishita, M., Kim, S., Ako, J., Hashimoto, M., lijima, K., et al. Estrogen receptor beta is involved in the anorectic action of estrogen. Int J Obes Relat Metab Disord. 2002,26:1103-9.

[141] Isgor, C., Cecchi, M., Kabbaj, M., Akil, H., Watson, S. J. Estrogen receptor beta in the paraventricular nucleus of hypothalamus regulates the neuroendocrine response to stress and is regulated by corticosterone. Neuroscience. 2003,121:837-45.

[142] Bao, A. M., Hestiantoro, A., Van Someren, E. J., Swaab, D. F., Zhou, J. N. Colocalization of corticotropin-releasing hormone and oestrogen receptor-alpha in the paraventricular nucleus of the hypothalamus in mood disorders. Brain. 2005,128:1301-13.

[143] Kelley, A. E., Baldo, B. A., Pratt, W. E., Will, M. J. Corticostriatal-hypothalamic circuitry and food motivation: integration of energy, action and reward. Physiology \& behavior. 2005,86:773-95.

[144] Izzo, E., Sanna, P. P., Koob, G. F. Impairment of dopaminergic system function after chronic treatment with corticotropin-releasing factor. Pharmacology, biochemistry, and behavior. 2005,81:701-8. 
[145] Harfstrand, A., Fuxe, K., Cintra, A., Agnati, L. F., Zini, I., Wikstrom, A. C., et al. Glucocorticoid receptor immunoreactivity in monoaminergic neurons of rat brain. Proceedings of the National Academy of Sciences of the United States of America. 1986,83:9779-83.

[146] Sauvage, M., Steckler, T. Detection of corticotropin-releasing hormone receptor 1 immunoreactivity in cholinergic, dopaminergic and noradrenergic neurons of the murine basal forebrain and brainstem nuclei-potential implication for arousal and attention. Neuroscience. 2001,104:643-52.

[147] Swanson, L. W., Sawchenko, P. E., Rivier, J., Vale, W. W. Organization of ovine corticotropinreleasing factor immunoreactive cells and fibers in the rat brain: an immunohistochemical study. Neuroendocrinology. 1983,36:165-86.

[148] Kasahara, M., Groenink, L., Olivier, B., Sarnyai, Z. Corticotropin-releasing factor (CRF) overexpression down-regulates hippocampal dopamine receptor protein expression and CREB activation in mice. Neuro Endocrinol Lett. 2011,32:193-8.

[149] Anisman, H., Matheson, K. Stress, depression, and anhedonia: caveats concerning animal models. Neuroscience and biobehavioral reviews. 2005,29:525-46.

[150] Koob, G., Kreek, M. J. Stress, dysregulation of drug reward pathways, and the transition to drug dependence. The American journal of psychiatry. 2007,164:1149-59.

[151] Koob, G. F., Le Moal, M. Drug addiction, dysregulation of reward, and allostasis.

Neuropsychopharmacology. 2001,24:97-129.

[152] Cottone, P., Sabino, V., Roberto, M., Bajo, M., Pockros, L., Frihauf, J. B., et al. CRF system recruitment mediates dark side of compulsive eating. Proceedings of the National Academy of Sciences of the United States of America. 2009,106:20016-20.

[153] Grant, K. A., Shively, C. A., Nader, M. A., Ehrenkaufer, R. L., Line, S. W., Morton, T. E., et al. Effect of social status on striatal dopamine D2 receptor binding characteristics in cynomolgus monkeys assessed with positron emission tomography. Synapse (New York, N.Y. 1998,29:80-3.

[154] Morgan, D., Grant, K. A., Gage, H. D., Mach, R. H., Kaplan, J. R., Prioleau, O., et al. Social dominance in monkeys: dopamine D2 receptors and cocaine self-administration. Nature neuroscience. 2002,5:169-74.

[155] Kaplan, J. R., Manuck, S. B., Fontenot, M. B., Mann, J. J. Central nervous system monoamine correlates of social dominance in cynomolgus monkeys (Macaca fascicularis). Neuropsychopharmacology. 2002,26:431-43.

[156] Volkow, N. D., Fowler, J. S., Wang, G. J. The addicted human brain: insights from imaging studies. The Journal of clinical investigation. 2003,111:1444-51.

[157] Volkow, N. D., Wise, R. A. How can drug addiction help us understand obesity? Nature neuroscience. 2005,8:555-60.

[158] Wang, G. J., Volkow, N. D., Logan, J., Pappas, N. R., Wong, C. T., Zhu, W., et al. Brain dopamine and obesity. Lancet. 2001,357:354-7.

[159] Geiger, B. M., Haburcak, M., Avena, N. M., Moyer, M. C., Hoebel, B. G., Pothos, E. N. Deficits of mesolimbic dopamine neurotransmission in rat dietary obesity. Neuroscience. 2009,159:1193-9.

[160] Lee, A. K., Mojtahed-Jaberi, M., Kyriakou, T., Aldecoa-Otalora Astarloa, E., Arno, M., Marshall, N. J., et al. Effect of high-fat feeding on expression of genes controlling availability of dopamine in mouse hypothalamus. Nutrition (Burbank, Los Angeles County, Calif. 2009.

[161] Johnson, P. M., Kenny, P. J. Dopamine D2 receptors in addiction-like reward dysfunction and compulsive eating in obese rats. Nature neuroscience. 2010,13:635-41.

[162] Blum, K., Sheridan, P. J., Wood, R. C., Braverman, E. R., Chen, T. J., Cull, J. G., et al. The D2 dopamine receptor gene as a determinant of reward deficiency syndrome. J R Soc Med. 1996,89:396-400.

[163] Tomasi, D., Volkow, N. D. Striatocortical pathway dysfunction in addiction and obesity: differences and similarities. Critical reviews in biochemistry and molecular biology. 2013,48:1-19.

[164] Small, D. M., Jones-Gotman, M., Dagher, A. Feeding-induced dopamine release in dorsal striatum correlates with meal pleasantness ratings in healthy human volunteers. Neurolmage. 2003,19:1709-15. 
[165] Di Chiara, G., Imperato, A. Drugs abused by humans preferentially increase synaptic dopamine concentrations in the mesolimbic system of freely moving rats. Proceedings of the National Academy of Sciences of the United States of America. 1988,85:5274-8.

[166] Rada, P., Avena, N. M., Hoebel, B. G. Daily bingeing on sugar repeatedly releases dopamine in the accumbens shell. Neuroscience. 2005,134:737-44.

[167] Lynch, W. J., Roth, M. E., Carroll, M. E. Biological basis of sex differences in drug abuse: preclinical and clinical studies. Psychopharmacology. 2002,164:121-37.

[168] Becker, J. B. Direct effect of 17 beta-estradiol on striatum: sex differences in dopamine release.

Synapse (New York, N.Y. 1990,5:157-64.

[169] Becker, J. B. Gender differences in dopaminergic function in striatum and nucleus accumbens.

Pharmacology, biochemistry, and behavior. 1999,64:803-12.

[170] Lammers, C. H., D'Souza, U., Qin, Z. H., Lee, S. H., Yajima, S., Mouradian, M. M. Regulation of striatal dopamine receptors by estrogen. Synapse (New York, N.Y. 1999,34:222-7.

[171] Czoty, P. W., Riddick, N. V., Gage, H. D., Sandridge, M., Nader, S. H., Garg, S., et al. Effect of menstrual cycle phase on dopamine D2 receptor availability in female cynomolgus monkeys.

Neuropsychopharmacology. 2009,34:548-54.

[172] Bazzett, T. J., Becker, J. B. Sex differences in the rapid and acute effects of estrogen on striatal D2 dopamine receptor binding. Brain research. 1994,637:163-72.

[173] Cummings, J. A., Jagannathan, L., Jackson, L. R., Becker, J. B. Sex differences in the effects of estradiol in the nucleus accumbens and striatum on the response to cocaine: neurochemistry and behavior. Drug Alcohol Depend. 2014,135:22-8.

[174] Hu, M., Crombag, H. S., Robinson, T. E., Becker, J. B. Biological basis of sex differences in the propensity to self-administer cocaine. Neuropsychopharmacology. 2004,29:81-5.

[175] Beery, A. K., Zucker, I. Sex bias in neuroscience and biomedical research. Neuroscience and biobehavioral reviews. 2011,35:565-72.

[176] Suglia, S. F., Duarte, C. S., Chambers, E. C., Boynton-Jarrett, R. Cumulative social risk and obesity in early childhood. Pediatrics. 2012,129:e1173-9.

[177] Noll, J. G., Zeller, M. H., Trickett, P. K., Putnam, F. W. Obesity risk for female victims of childhood sexual abuse: a prospective study. Pediatrics. 2007,120:e61-7.

[178] Schneiderman, J. U., Mennen, F. E., Negriff, S., Trickett, P. K. Overweight and obesity among maltreated young adolescents. Child Abuse Negl. 2012,36:370-8.

[179] Koch, F. S., Sepa, A., Ludvigsson, J. Psychological stress and obesity. J Pediatr. 2008,153:839-44.

[180] Moens, E., Braet, C., Bosmans, G., Rosseel, Y. Unfavourable family characteristics and their associations with childhood obesity: a cross-sectional study. European eating disorders review : the journal of the Eating Disorders Association. 2009,17:315-23.

[181] Gundersen, C., Mahatmya, D., Garasky, S., Lohman, B. Linking psychosocial stressors and childhood obesity. Obes Rev. 2011,12:e54-63.

[182] Anderson, S. E., Gooze, R. A., Lemeshow, S., Whitaker, R. C. Quality of early maternal-child relationship and risk of adolescent obesity. Pediatrics. 2012,129:132-40. 


\section{ESTRADIOL vs CORTISOL}

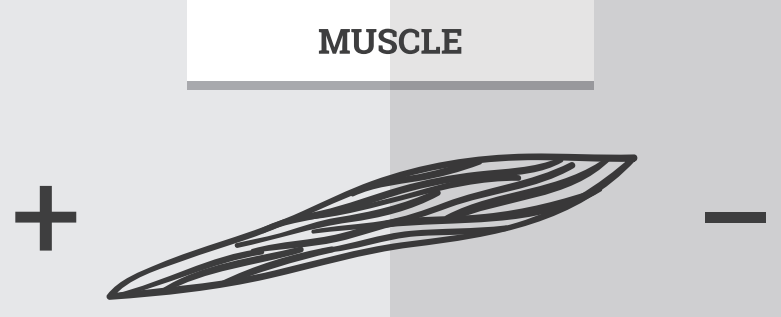

GLUCOSE UPTAKE

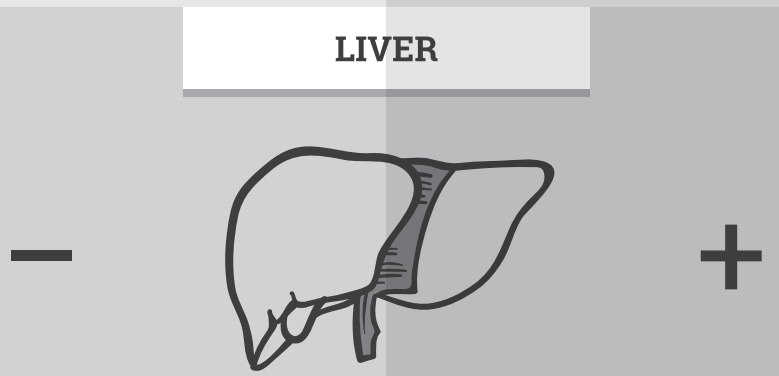

GLUCOSE PRODUCTION

PANCREAS

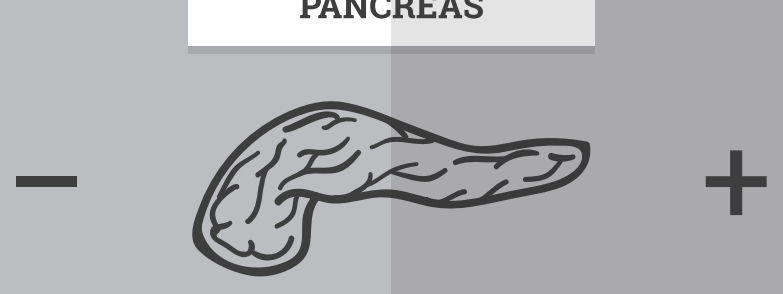

INSULIN RELEASE

ADIPOCYTES

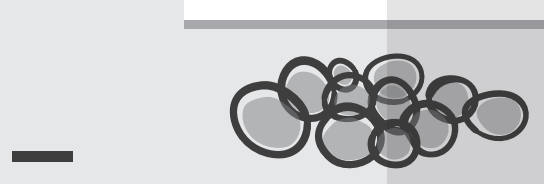

LIPOGENESIS

LEPTIN RELEASE

INFLAMMATION

\section{BRAIN}

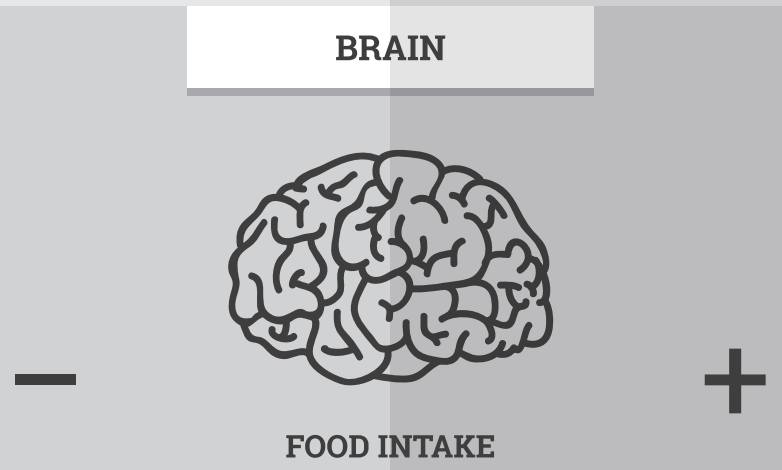

FOOD INTAKE

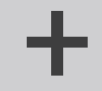

NPY

$\mathrm{MCH}$

GHRELIN / AGRP

LEPTIN RESISTANCE

INSULIN RESISTANCE 